\title{
Fuzzy Comprehensive Evaluation Model for Eco-environmental Carrying Capacity Related to Water in Tieling Section of Liao River Basins, China
}

\author{
H. Wang \\ Liaoning Province Key Laboratory of Basin Pollution Control \\ Liaoning Academy of Environmental Sciences \\ Shengyang 110000, China
}

\begin{abstract}
Water ecological carrying capacity of basin is important basis to whether coordinated development for basin resources, environmental and economic society, is important means to impetus sustainable development of water ecological environment and social economy. Take Tieling section of Liao River as an example, through the diagnosis of the ecological environment problem, according to the water resource, environment, and the social economy, 8 indexes are selected to establish evaluating indicator system, then use the fuzzy comprehensive evaluation method to calculates water ecological carrying capacity in Tieling section of Liao River. Result demonstrated: in 2009, the score value of water ecological carrying capacity of Tieling section is greater than that of 1999. The little advance of ecoenvironmental carrying capacity related to water in 2009 comparing with in 1999 was due to the decrease of water demand and waste water discharge in per unit industrial added value, and the advanced level of waste control.
\end{abstract}

Keywords- Eco-environmental Carrying Capacity, sustainable development, advanced level of waste control

\section{INTRODUCTION}

Eco-environmental problem of basin had made rational development and utilization of ecoenvironmental resources related to water a significant issue for development of social economy (Falkenmark, 1998). The resources grabbed by human beings severely demolished the balance of ecosystem which threatens the ecological safety and health. Under the intensive human activities dominated by exploitation and utilization of water resources and discharge pollutions, the conflict between ecological protection and economic development were becoming manifest (Miloradov, 1995). The decrease of eco-environmental carrying capacity accordingly became the bottleneck of development of social economy (Mao, 2001). For solving this fateful trouble, ecoenvironmental carrying capacity should be utilized scientifically, meanwhile best social and economic benefit being taken. To make good use of the ecoenvironmental carrying capacity related to water, it is necessary to find out the current situation of ecoenvironment, also comprehensively evaluate the trend of its development.
Water resource in Liao River basin is limited due to its seasonal uneven distribution and excessive pollutants discharge sharpening the lack of useable water resource. Tieling, upstream of Liao stream, was the first section in Liaoning Province of Liao stream conflux by West and East Liao River. The ecosystem of Tieling section of Liao stream is vulnerable due to the lack of water resources and recovery of contamination. The objective of this research was to evaluate the eco-environmental carrying capacity related to water in Tieling section and provide a scientific basis for further rational eco-environment protection and social economic sustainable development.

\section{Study area}

The Liao River basins (Fig. 1), which originates from Bald-head Hill of Qilaotu Mountains and flows into the Bo Sea near Panjin City, are located in the southwest of northeastern China, at $116^{\circ} 54^{\prime}-125^{\circ} 32^{\prime} \mathrm{E}$ and $38^{\circ} 48^{\prime}-$ $45 \circ 17^{\prime} \mathrm{N}$, bordered by the Liaodong, Jidong Country and Yalu Basins in the east, Qilaotu Mountains, Nuluerhu Mountains, Yiwulv Mountains, Luan river and Big, Small Lin River in the west and southwest, Song-Liao River watershed and the Songhuajiang River Basins in the north, Bo Sea in the south. The Liao River Basins, 219,600 square kilometers in total area, consist of the west and east Liao River, Liao River, Wai Liao River, Big Liao River and many branches.

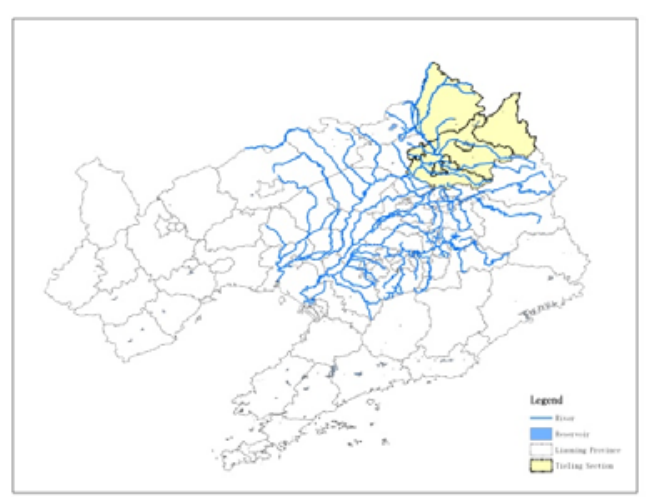

Figure 1. River system map of Liao River basin and Tieling section 
Tieling locates in north of Liaoning Province at $123 \circ 27^{\prime}-125^{\circ} 06^{\prime} \mathrm{E}$ and $41 \circ 59^{\prime}-43^{\circ} 29^{\prime} \mathrm{N}$, with the area of 638 square kilometers and population of $3,054,000$, which dominate four urban districts, three countries, and two country-level cities. The main stream of Liao River within the boundaries of this city, which belongs to the upper reaches of Liao River within Liaoning Province, is 170 kilometers in length (Fig. 2). Tieling is abundant with water resources, with 39 rivers which basin areas beyond 100 square kilometers within the boundaries of it.

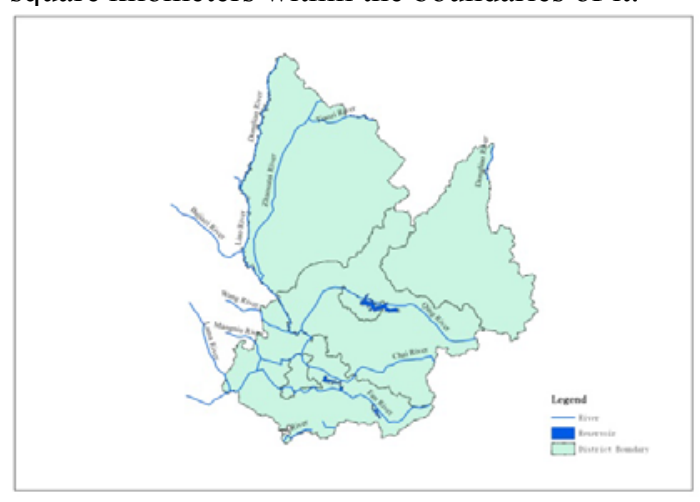

Figure 2. River system map of Tieling

As a significant base of energy source and farm produce, sub centre city of mid-city group of Liaoning Province, Tieling is a modernized comprehensive city depending on the development of machining, electric power, and farm product processing. GDP of Tieling was 605.70 billion Yuan at 2009 with the velocity of development approximately $18 \%$ comparing with last year.

\section{DATA AND METHOD}

\section{A. Data sources}

The data used in this paper were collected from Water Resources Communique of Tieling 2000-2008, Investigation of source of pollution 2007-2009 and Tieling Statistical Yearbook 2000-2008 (Water Conservancy Bureau, 2008; Tieling Environmental Bureau, 2009; Tieling Statistical Bureau, 2008), which include basic situation and discharge of contamination of Tieling, such as the population, land area, average annual precipitation, total water resources, total water supply, COD and NH3-N emission, and so on. The values of evaluation factors were calculated from the original data. In addition, the indices of the gradation of each evaluation factor were determined by consulting the specialists in the related fields (Rijiberman, 2000; Li, 2009).

\section{B. Fuzzy comprehensive evaluation model}

Giving two finite groups $U=\left[u_{1}, u_{2}, \ldots, u_{m}\right], \mathbf{V}=\left[v_{1}\right.$, $\left.v_{2}, \ldots, v_{n}\right], U$ stands for the aggregate composed of all the evaluation factors; $V$ stands for the aggregate composed of all the remark grades; $r_{i j}$ is the judge result of evaluation factor $u_{i}$ to remark $v_{j}$, so the judge decisionmaking matrix of $\mathrm{m}$ evaluation factors is as follows (Huang, 2002a; Huang, 2002b):

$$
R=\left[\begin{array}{ccccc}
r_{11} & r_{12} & r_{13} & \cdots & r_{1 n} \\
r_{21} & r_{22} & r_{23} & \cdots & r_{2 n} \\
\cdots & \cdots & \cdots & \cdots & \cdots \\
r_{m 1} & r_{m 2} & r_{m 3} & \cdots & r_{m n}
\end{array}\right]
$$

where $R$ is the fuzzy connection of $U$ to $V$, and $R_{i}$ is the fuzzy connection of $u_{i}$ to $V$. If the weight of each evaluation factor is $A=\left[a_{1}, a_{2}, \ldots, a_{m}\right]$ ( $A$ is a fuzzy subclass of aggregate $U, 0 \leq a_{i} \leq 1$, and the sum of $a_{i}$ is 1 ), one fuzzy subclass of aggregate $V$ can be worked out by applying the synthetic operation of fuzzy transform, which is the comprehensive evaluation result:

$B=A \cdot R=\left[b_{1}, b_{2}, \ldots, b_{n}\right]$

where $B$ stands for a fuzzy aggregate of $V$. Fuzzy transform $A \cdot R$ changes into common matrix calculation, which refers to many factors in all directions and is suitable for multi-factors sequence. The calculation can be described as follows:

$$
b_{j}=\min \left\{1, \sum_{i=1}^{m} a_{j} r_{i j}\right\}
$$

\section{Selection and gradation of evaluation factors}

It is essential to establish a criteria system to evaluate eco-environmental carrying capacity related to water for it is a complicated definition relating to lots of aspects. Thus, the evaluation of eco-environmental carrying capacity related to water should be multi-objective systems, which incarnate the equilibrium of water resources system, water environment system, and water ecology system. The indexes system established under certain principle is an aggregation containing different characteristic properties, which can reflect the water resources conditions, water ecological environments status in quo, the exploitation and utilization, and relationship between economic progress and water ecological environments conservation, such as Per capita water resources available volume (m3/PER), 10000 Yuan of industrial added value of water demand (m3/104Yuan), 10000 Yuan of industrial added value of waste water discharge ( $t$ /104Yuan), Repeating utilization of industrial water, Industrial waste water discharge rate (\%), 10000 Yuan of industrial added value of waste water discharge ( $\mathrm{t}$ /104Yuan), 10000 Yuan of added value of COD discharge ( $t$ /104Yuan), 10000 Yuan of added value of NH4-N discharge (t/104Yuan), and Per capita GDP (Yuan/PER).

\section{Calculation of judge matrix}

According to the significance of evaluation factors on the eco-environmental carrying capacity related to water, above-mentioned factors are classified to three levels expressed as $V_{1}, V_{2}$ and $V_{3}$. The class index of each factor will be calculated according to the regional situation and consulting domain experts (Table 1). In this classification, the grade of $V_{3}$ stands for the worst situation of low potential water extraction and of 
unsatisfactory water ecological environment in which eco-environmental carrying capacity related to water has almost reached the high point. Disrupted water ecological environment would be a bottleneck to regional economic development and relevant measures should be taken. The grade of $V_{l}$ stands for the best situation that means in this region eco-environmental related to water still have a bigger carrying capacity with low water usage and economic development. Therefore, it can guarantee the water demand for regional development.

\section{TABLE 1: COMPREHENSIVE EVALUATION OF} THE VALUE CLASSIFICATION

\begin{tabular}{|c|c|c|c|}
\hline \multirow{2}{*}{ Evaluation factors set $U$} & \multicolumn{3}{|c|}{ Judgment set $V$} \\
\hline & $\overline{V_{1}}$ & $V_{2}$ & $V_{3}$ \\
\hline $\begin{array}{l}\text { Per capita water resources available } \\
\text { volume }\left(\mathrm{m}^{3} / \mathrm{PER}\right)\end{array}$ & $>8800$ & $\begin{array}{l}4400- \\
8800\end{array}$ & $<4400$ \\
\hline $\begin{array}{l}10000 \text { Yuan of industrial added } \\
\text { value of water demand } \\
\left(\mathrm{m}^{3} / 10^{4} \text { Yuan }\right)\end{array}$ & $<50$ & $50-127$ & $>127$ \\
\hline $\begin{array}{l}\text { Repeating utilization of industrial } \\
\text { water }(\%)\end{array}$ & $>85$ & $40-85$ & $<40$ \\
\hline $\begin{array}{l}\text { Industrial waste water meeting } \\
\text { discharge standards }(\%)\end{array}$ & $>90$ & $80-90$ & $<80$ \\
\hline $\begin{array}{l}10000 \text { Yuan of industrial added } \\
\text { value of waste water discharge } \\
\text { ( } / 10^{4} \text { Yuan) }\end{array}$ & $<10$ & $19-10$ & $>19$ \\
\hline $\begin{array}{l}10000 \text { Yuan of added value of } \\
\text { COD discharge }\left(10^{-3} \mathrm{t} / 10^{4} \text { Yuan }\right)\end{array}$ & $<3.54$ & $3.54-24$ & $>24$ \\
\hline $\begin{array}{l}10000 \text { Yuan of added value of } \\
\mathrm{NH}_{4}-\mathrm{N} \text { discharge }\left(10^{-4} \mathrm{t} / 10^{4} \text { Yuan }\right)\end{array}$ & $<0.15$ & $0.15-3.50$ & $>3.50$ \\
\hline Per capita GDP (Yuan/PER) & $\begin{array}{l}>5200 \\
0\end{array}$ & $\begin{array}{l}23000- \\
52000\end{array}$ & $<23000$ \\
\hline Scores & 0.95 & 0.5 & 0.05 \\
\hline
\end{tabular}

The situation of regional eco-environmental carrying capacity related to water is more delightful. The situation of grade $V_{2}$, which is in a middle position of above two, means this region still has potential water available though eco-environmental carrying capacity related to water has been used in a large scale.

For giving a better reflection on situation of every class of eco-environmental carrying capacity related to water the three levels of $V_{1}, V_{2}$ and $V_{3}$ are graded between 0 and 1 as $\alpha_{1}=0.95, \alpha_{2}=0.5, \alpha_{3}=0.05$. Therefore, the impact degree of factors to eco-environmental carrying capacity related to water in every class will be quantified. The higher the grade is the grater the potential of ecoenvironmental carrying capacity related to water will be. The value of $\alpha_{j}$ and the value of $b_{j}$ in $B$ matrix are used in comprehensive evaluation, using the following equation:

$$
a=\frac{\sum_{j=1}^{3} b_{j}^{k} a_{j}}{\sum_{j=1}^{3} b_{j}^{k}}
$$

According to the evaluation factors of the actual numerical control of the factors of grade indexes to judge calculation analysis of the matrix $R$ membership function values $r_{i j}$. In order to eliminate the defect of slight difference of values in each grade and jumping phenomenon existing in different evaluation grades, it is necessary to dispose membership function fuzzily and to let all grades transit smoothly. As far as $V_{2}$ is concerned, the membership degree in the midpoint is 1 , the membership degree in the two sides is 0.5 , and the value descends linearly from the midpoint to the two sides. As far as $V_{1}$ and $V_{3}$ are concerned, if the distance to the critical value is longer, the membership degree will be higher; if it is in the critical value, the membership degree of the two edges will be 0.5 . According to these rules, the equation for calculating each membership degree can be constructed. If the critical value of $V_{1}$ and $V_{2}$ is $\mathrm{k} 1$, the critical value of $V_{2}$ and $V_{3}$ is $k_{3}$, and the value of $V_{2}$ is $k_{2}$, $k_{2}=\left(k_{1}+k_{3}\right) / 2$. About evaluation factors $u_{1}, u_{2}, u_{3}, u_{4}, u_{5}$, the equations of each membership function $\left(\mu v_{j}\left(u_{i}\right)\right)$ can be denoted as follows:

$$
\begin{aligned}
& \mu_{v 1}\left(u_{i}\right)=\left\{\begin{array}{cc}
0.5\left(1+\frac{u_{\mathrm{i}}-k_{1}}{u_{\mathrm{i}}-k_{2}}\right) & u_{i} \geq k_{1} \\
0.5\left(1-\frac{k_{1}-u_{i}}{k_{1}-k_{2}}\right) & k_{2} \leq u_{i}<k_{1} \\
0 & u_{i}<k_{2}
\end{array}\right. \\
& \mu_{v 2}\left(u_{i}\right)= \begin{cases}0.5\left(1-\frac{u_{i}-k_{1}}{u_{i}-k_{2}}\right) & u_{i} \geq k_{1} \\
0.5\left(1+\frac{k_{1}-u_{i}}{k_{1}-k_{2}}\right) & k_{2} \leq u_{i}<k_{1} \\
0.5\left(1+\frac{u_{i}-k_{3}}{k_{2}-k_{3}}\right) & k_{3} \leq u_{i}<k_{2} \\
0.5\left(1-\frac{k_{3}-u_{i}}{k_{2}-u_{i}}\right) & u_{i}<k_{3}\end{cases} \\
& \mu_{v 3}\left(u_{i}\right)=\left\{\begin{array}{cl}
0 & u_{i} \geq k_{2} \\
0.5\left(1-\frac{u_{i}-k_{3}}{k_{2}-k_{3}}\right) & k_{3} \leq u_{i}<k_{2} \\
0.5\left(1+\frac{k_{3}-u_{i}}{k_{2}-u_{i}}\right) & u_{i} \leq k_{3}
\end{array}\right.
\end{aligned}
$$

\section{RESULT AND DISCUSSION}

Tieling section belonging to the upper reaches of the Liao stream was representative sample of upper stream of Liao river basin. According to the eco-environment, society and economy situation of Liao river basin, we evaluated eco-environmental carrying capacity related to water of by analysis nine chosen indices. Evaluation factor results in Table 2 .

\begin{tabular}{|c|c|c|}
\hline Evaluation factors & 1999 & 2009 \\
\hline $\begin{array}{l}\text { Per capita water resources available volume } \\
\left(\mathrm{m}^{3} / \mathrm{PER}\right)\end{array}$ & 778.40 & 1174.00 \\
\hline $\begin{array}{l}10000 \text { Yuan of industrial added value of } \\
\text { water demand }\left(\mathrm{m}^{3} / 10^{4} \text { Yuan }\right)\end{array}$ & 388.71 & 54.74 \\
\hline Repeating utilization of industrial water (\%) & 61.31 & 95.53 \\
\hline $\begin{array}{l}\text { Industrial waste water meeting discharge } \\
\text { standards }(\%)\end{array}$ & 80.48 & 90.10 \\
\hline $\begin{array}{l}10000 \text { Yuan of industrial added value of } \\
\text { waste water discharge }\left(t / 10^{4} \text { Yuan }\right)\end{array}$ & 41.93 & 7.98 \\
\hline $\begin{array}{l}10000 \text { Yuan of added value of COD } \\
\text { discharge }\left(10^{-3} \mathrm{t} / 10^{4} \text { Yuan }\right)\end{array}$ & 48.63 & 1.99 \\
\hline $\begin{array}{l}10000 \text { Yuan of added value of NH4-N } \\
\text { discharge }\left(10^{-4} \mathrm{t} / 10^{4} \text { Yuan }\right)\end{array}$ & 2.07 & 0.15 \\
\hline Per capita GDP (Yuan/PER) & 28691.69 & 31385.44 \\
\hline
\end{tabular}

TABLE 2: ECO-ENVIRONMENTAL CARRYING CAPACITY RELATED TO WATER INDEX SYSTEM OF TIELING SECTION 
From the value of each evaluation factor in Table 2, the membership degree $r_{i j}$ can be calculated according to the equations (2)-(4), in which $r i 1=\mu_{v 1}\left(u_{i}\right), r_{i 2}=\mu_{v 2}(u i)$, $r_{i 3}=\mu_{v 3}\left(u_{i}\right)$. After considering the influence degree of each evaluation index on eco-environmental carrying capacity related to water and the intersection of different index, each evaluation factor was endowed with different weight which can be got by level analysis method, namely $A=(0.1,0.15,0.1,0.1,0.15,0.15,0.15$, and 0.1$)$. The final evaluation matrix of eco-environmental carrying capacity related to water can be obtained by using the equation $B=A \bullet R$. The integrated evaluation of eco-environmental carrying capacity related to water of Tieling section was shown in Table 3.

Table 3: Eco-environmental carrying capacity related to water integrated evaluation form of Tieling section

\begin{tabular}{l|c|l|c|c}
\hline \multicolumn{2}{c|}{ Section } & $V_{1}$ & $V_{2}$ & \multicolumn{2}{c}{$V_{3}$} & Scores \\
\hline 1999 & 0.194 & 0.312 & 0.495 & 0.365 \\
\hline 2009 & 0.494 & 0.365 & 0.141 & 0.659 \\
\hline
\end{tabular}

Tieling was located in the upstream of Liao River, and the evaluation of eco-environmental carrying capacity related to water was essential due to its vulnerable ecosystem and important location. This research firstly evaluated the eco-environmental carrying capacity related to water in Tieling section, also compared the trend of eco-environmental carrying capacity in 1999-2009. The main conclusions were as follows:

(1) Considering the situation of the water resources, water ecological environments, the exploitation and utilization, and relationship between economic progress and water ecological environments conservation, eight indexes were chosen to establish the indexes system. There were Per capita water resources available volume, 10000 Yuan of industrial added value of water demand, 10000 Yuan of industrial added value of waste water discharge, Repeating utilization of industrial water, Industrial waste water discharge rate, 10000 Yuan of industrial added value of waste water discharge, 10000 Yuan of added value of COD discharge, 10000 Yuan of added value of $\mathrm{NH}_{4}-\mathrm{N}$ discharge, and Per capita GDP.

(2) Eco-environmental carrying capacity related to water of Tieling in 2009 reached a considerable scale, $b_{j}$ comprehensive evaluation of the results of the $V_{1}$ membership was 0.494 , and right $V_{2}$ membership was 0.365 , and the score value of 0.659 greater than that of 19990.365 . The little advance of eco-environmental carrying capacity related to water in 2009 comparing with in 1999 was due to the decrease of water demand and waste water discharge in per unit industrial added value, and the advanced level of waste control.

\section{ACKNOWLEDGEMENTS}

This work was financially supported by National Special Science and Technology program water pollution control and treatment (2012ZX07505001).

\section{REFERENCES}

[1] Falkenmark M, Lundqvist J. Towards water security: political determination and human adaptation crucial. Nature Resources Forum [J]. 1998, 21(1): 37-51.

[2] Huang CF. An application of calculated fuzzy risk [J]. Inf Sci, 2002a, 142(1):37-56.

[3] Huang CF. Information diffusion techniques and small sample problem [J]. Int J Inf Technol Decis Mak, 2002b, 1(2):229-249.

[4] Li Gong, Chunling Jin. Fuzzy Comprehensive Evaluation for Carrying Capacity of Regional Water Resources [J]. Water Resour Manage, 2009, 23:2505-2513.

[5] Miloradov R M, Cukic Z. Water resources assessment as the basic tool for sustainable and environmentally sound river basin management [J]. Water Science and Technology, 1995, 32(5-6): 45-53.

[6] Mao Xiaohui. Study on sustainable utilization strategy of water resources in Tarim River Basin [J]. Arid Land Geography, 2001, 24(2): 136-140. (in Chinese)

[7] Rijiberman J. Different approaches to assessment of design management of sustainable urban water system [J]. Environment Impact Assessment Review, 2000, 129(3): 333-345. 